“드 2013 IEEE. Personal use of this material is permitted. Permission from IEEE must be obtained for all other uses, in any current or future media, including reprinting/republishing this material for advertising or promotional purposes, creating new collective works, for resale or redistribution to servers or lists, or reuse of any copyrighted component of this work in other works." 


\title{
SocialCycle
}

\section{What Can a Mobile App Do To Encourage Cycling?}

\author{
Karla Felix Navarro, Valerie Gay, Loic Golliard, Benjamin Johnston, Peter Leijdekkers, \\ Ewan Vaughan, Xun Wang, and Mary-Anne Williams \\ Faculty of Engineering and IT \\ UTS, University of Technology, Sydney, Australia
}

\begin{abstract}
Traffic congestion presents significant environmental, social and economic costs. Encouraging people to cycle and use other forms of alternate transportation is one important aspect of addressing these problems. However, many city councils face significant difficulties in educating citizens and encouraging them to form new habits around these alternate forms of transport. Mobile devices present a great opportunity to effect such positive behavior change. In this paper we discuss the results of a survey aimed at understanding how mobile devices can be used to encourage cycling and/or improve the cycling experience. We use the results of the survey to design and develop a mobile app called SocialCycle, which purpose is to encourage users to start cycling and to increase the number of trips that existing riders take by bicycle.
\end{abstract}

Index Terms - Smarter Planet; Smart Cities; Social networking; Social Aware Technology; Internet of Things; Privacy and Security, Gamification.

\section{INTRODUCTION}

The SocialCycle Project team at the University of Technology, Sydney is working on a collaborative project integrating their expertise in sensor networks, mobile health applications, augmented reality, computer engineering, analytics and robotics. The objective of the project is to promote a more sustainable mode of transport in the city of Sydney by making cycling a more attractive, socially normalized [1] and enjoyable experience amongst its population through the use of ubiquitous mobile applications.

Sydney is the largest capital city in Australia with over 4.63 million inhabitants [2]. Its population is projected to grow to over 5 million by 2020 [3]. Like many other global cities, Sydney faces increasingly complex challenges in transport, such as growing urban populations, increased pollution, growing traffic congestion and ageing public transport infrastructure. Inefficient transportation poses significant burdens to health, the economy and global warming. Motor vehicles contribute over $70 \%$ of NOx emissions in Sydney [4] and the Bureau of Infrastructure Transport and Regional Economics estimates that the cost of traffic congestion will grow from $\$ 5.6 \mathrm{~B}$ in 2013 to $\$ 7.7 \mathrm{~B}$ by 2020 [5].

Currently, Sydney's public transport system features a network of bus, train, light rail and ferry services. However, in 2005 Sydney residents made 15.7 million trips each weekday with $70 \%$ of these trips being made by car [6]. This behavior is primarily due to the fact that Sydney's train system was designed and developed in 1914 and since then the network not been significantly expanded. Some lines are also extremely crowded during business hours. New highly populated areas (such as Sydney's North West) are not well served and buses face traffic congestion.

In 2007, the City of Sydney created an action plan [7] to increase the use of cycling, by creating and maintaining a comfortable and bicycle friendly environment in Sydney to encourage more residents, visitors and workers onto bicycles; improving cycling safety; promoting the benefits of cycling; and increasing the number of trips made by bicycle in Sydney. The key targets the City of Sydney has set itself are:

- Increase the number of bicycle trips made in the City of Sydney, as a percentage of total trips, from less than two per cent in 2006 to five per cent by 2011 , and to 10 per cent by 2016;

- Increase the number of bicycle trips between two and 20 $\mathrm{km}$ made in the City of Sydney, as a percentage of total trips to 20 per cent by 2016 ;

- Achieve a minimum 80 per cent good level of confidence and comfort for cyclists that ride in the City of Sydney by 2016;

The City of Sydney has conducted several surveys that aim to understand the needs of cyclists and the factors that prevent non-cyclists from taking up cycling.

The City of Sydney has identified the creation of contagious behaviors in social networks as a crucial part of the adoption of cycling. Through an in-depth social research study they found seven of fifteen cyclists had begun cycling as a result of the influence of partners and friends [8]. Many of the enablers of cycling are socially based. They include:

- Perceived safety: these fears can be reduced through contact with friends who cycle.

- Legitimacy: cyclists 'need to sense that cycling is a legitimate, socially sanctioned activity' and that polite conversations about cycling can normalize the activity in their social networks [8].

- Confidence: this can be improved through familiarity and support from other cyclists. 
- Route Knowledge: potential cyclists who do not have a network of cycling friends may assume that a commute by bicycle would follow the same route on busy roads, as a regular motor-vehicle route.

- Employer Support: the workplace - its social environment and the end of trip facilities - is an important factor in travel choice.

The major challenge for the City of Sydney is its need to help citizens make better choices and to change their behavior by making cycling more attractive, useful and enjoyable, so that they chose to ride more often. Changing behavior is the major challenge: The City of Sydney cannot reach its targets unless it successfully changes a large number of people's behavior. There are many approaches to behavior modification which all involve learning and change. According to the 4Es approach of behavior change, there are four main strategies that result in successful behavior change [9]:

- Enablement by removing barriers to motivation and action.

- Encouragement by implementing reward schemes.

- Engagement by creating community actions.

- Exemplification by leading by example.

The City of Sydney has the opportunity to address the 4Es strategy through regulation and economic incentives. However it is not clear if citizens would respond as predicted.

In this paper the objective is to investigate the use of mobile devices to achieve the above-mentioned objectives of the City of Sydney focusing on the enablement, encouragement and engagement aspects. The paper is organized as follows: section 2 gives an overview of existing mobile apps for cycling. Section 3 describes the survey results we conducted related to the use and expectations of a mobile application for cycling. Based on the survey results we identified requirements and features for our mobile app, which are described in section 4 . Section 5 discuses the next steps and open issues.

\section{StAte of the ART ON MOBILE APPlicAtions FOR CYCLISTS}

Many mobile apps are available on Google Play and Apple Store that address the fitness, ride tracking, competition and transportation segment. These apps provide a range of features and functionalities but there is no single mobile app that addresses the specific needs of Sydney cyclists. The majority of cycling apps address the needs of regular cyclists as opposed to casual cyclists and non-cyclists who may need assistance and encouragement to take up cycling.

Endomondo [10] and RunKeeper [11] are the market leaders in fitness tracking by providing applications that enable users to record and share their workouts. However, these applications are general fitness apps and are not specific to cycling. They record fitness details of all kinds of sporting activities.

Some applications such as MapMyRide [12], iBike [13], cycle meter [14] or spokes NYC [15] enable users to save their progress and routes. They focus only on bike riding but mainly act as a diary, history keeping on routes and kilometers travelled, without providing any form of motivation or facilitate social interaction for cyclists to meet.

Strava [16] is another bike riding app focusing on performance and addresses professional riders. Its main objective is for riders to compete against each other. However, its use in cities can be dangerous [17].

Waze [18] aims to connect car drivers within cities but it could also be used by cyclists. It provides the best routes within a city based on feedback from other users. For example, users can report accidents and roads to be avoided due to roadwork. Waze is based on users using their mobile phone to report road conditions and share information with others to help enhance their journey. The idea of 'socializing' roads could also work for cycling.

TABLE I. APP COMPARISONS

\begin{tabular}{|l|c|c|c|c|c|}
\hline & Social & $\begin{array}{c}\text { Bike } \\
\text { only }\end{array}$ & Motivation & Beginners & Discovery \\
\hline Endomondo & $\sqrt{ }$ & $\times$ & $\sqrt{ }$ & $\sqrt{ }$ & $\times$ \\
\hline RunKeeper & $\sqrt{ }$ & $\times$ & $\sqrt{ }$ & $\sqrt{ }$ & $\times$ \\
\hline MapMyRide & $\times$ & $\sqrt{ }$ & $\times$ & $\times$ & $\times$ \\
\hline iBike & $\times$ & $\sqrt{ }$ & $\times$ & $\times$ & $\times$ \\
\hline cycle meter & $\times$ & $\sqrt{ }$ & $\times$ & $\times$ & $\times$ \\
\hline spokes NYC & $\times$ & $\sqrt{ }$ & $\times$ & $\times$ & $\sqrt{ }$ \\
\hline Strava & $\sqrt{ }$ & $\sqrt{ }$ & $\sqrt{ }$ & $\times$ & $\times$ \\
\hline Waze & $\sqrt{ }$ & $\times$ & $\sqrt{ }$ & $\sqrt{ }$ & $\sqrt{ }$ \\
\hline
\end{tabular}

Waze stood out as the app that aligns best with the 4Es described earlier. It can be used to discover, in real-time, new routes and encourages users to share information by offering rewards and bonuses. It supports community actions and allows mentors and veterans to help others. Users can interact and share useful information about routes and roads, which creates added value for users.

\section{SURVEY}

Governments and universities have conducted many surveys over the years to investigate the needs of cyclist. These surveys are mainly focused on sustainability and transport efficiency. Our objective is to explore the opportunities for behavior change using mobile apps. The survey comprised two parts:

- A survey to understand the reasons why Sydneysiders use bicycles, as well as their requirements and needs.

- A questionnaire addressing habits, challenges, information needed and opportunities that could be relevant to the user's behavioral change. Investigating what could we do with mobile apps to motivate users to use their bicycles more often. 
The first part of the survey was intended to replicate the outcomes of other surveys as a way to understand the individual needs and allow comparison with other surveys.

For the survey several criteria were selected to ensure the quality of the answers. We selected participants living in the City of Sydney since the SocialCycle app aims to target this population, and we surveyed people who already ride either for recreation purposes or to get to work.

We used a mix of open and closed questions. Most closed questions have an "other" option to allow for alternative answers. The last question explored the limitations of available mobile apps in the market from respondents who are currently using mobile apps to aid their bike rides.

The survey was created using Google Forms [19] and sent to Sydney cyclists in the period of March-April 2013. Twentytwo (22) questionnaires were collected.

Purpose: We found that Sydney bike riders cycle for a variety of reasons. $72 \%$ use their bike to ride to work or school, which confirms that we reached our target group. Most participants ride for fitness purposes $(86 \%)$ and/or recreational reasons to discover new places (72\%). Additionally, the "feel good" aspect of bike riding is important since it reduces the cost compared to using the car or public transportation $(59 \%)$ and the impact on the environment planet (77\%).

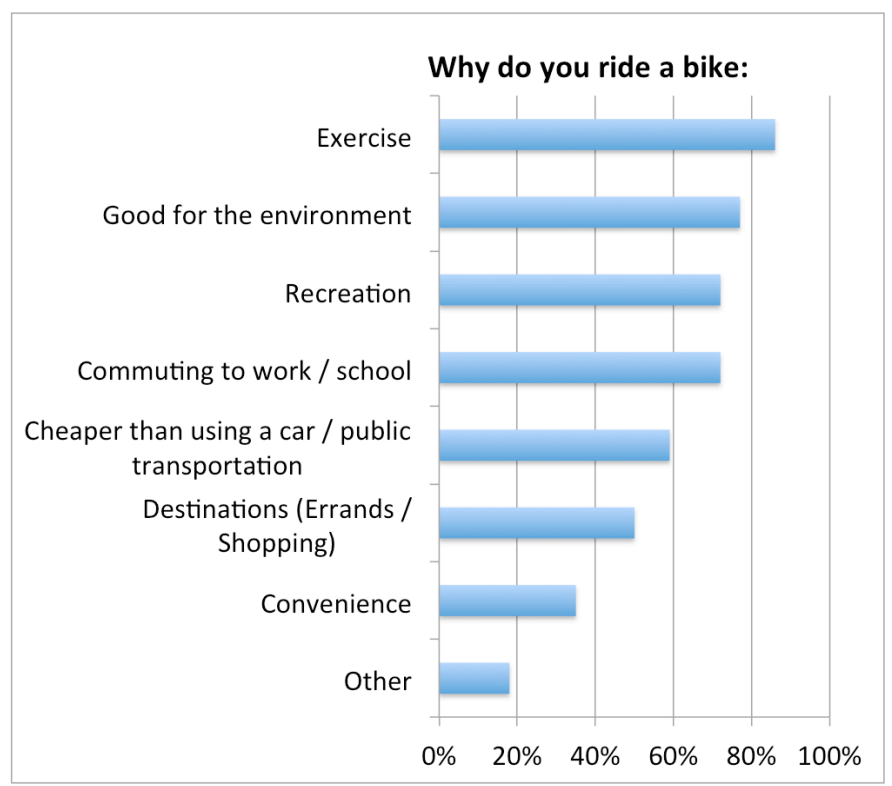

Fig. 1. Survey results

Barriers: Three main reasons appeared for not using the bicycle more often: cycling paths, safety and weather. The lack of cycling paths has been found as the main limitation for $59 \%$ of our respondents. The respondents indicated that they need more information on available bike lanes to reach their destination. The lack of information can be related to the fact that $50 \%$ indicated that they feel unsafe to ride in Sydney.

The geography and weather were an issue for 55\% of the respondents. For many the weather is either too hot or too wet to ride a bike. Also the geography plays a role. Sydney is very hilly and for $77 \%$ of the respondent is crucial to know where they could access a shower when they reach their destination (at work).

Information: Prior to their ride, participants would like to get information on available bike lanes $(100 \%)$, where they can have a shower (77\%) and park their bike (63\%). Many respondents $(81 \%)$ would like more information on their performance, such as kilometers travelled, calories burned, estimated time of arrival and audio assisted navigation (68\%).

Social aspects: Before planning their trip, $36 \%$ of the respondents indicated that it would be helpful to know who is currently riding in their area and $45 \%$ would like to read tips and comments from other riders about their route. $31 \%$ indicated that it would motivate them to find other people with whom they can ride together. $27 \%$ of the participants were keen to know who is riding in their proximity. $45 \%$ indicated that they would be willing to post tips and pictures after completing their ride.

Gamification: One of the objectives of the survey was to understand which gamification aspects cyclists would be interested in and what motivate them to ride more often. $60 \%$ is interested in some sort of reward when they cycle. $23 \%$ are interested in competing against their friends and see their position on a leaderboard. Participants were also willing to complete quests $(27 \%)$. Furthermore, $50 \%$ indicated to be interested in exploratory features such as discovering restaurants and cafes around them. $86 \%$ mentioned that cycling would be more fun if itineraries could be displayed to discover new places.

\section{REQUIREMENTS FOR SOCIALCYCLE}

The findings of the survey highlighted several important requirements that need to be addressed in order for the app to be successful. These are:

- Provision of accurate route information and location/availability of facilities at the destination.

- Access to social information and being able to network with other riders.

- Gamification and other entertainment features.

From the survey results we concluded that the first requirement is crucial whereas the social and gamification aspects where not required by all participants. These could be optional elements in the SocialCycle app.

\section{A. Accurate Trip and facilities information}

A challenging task for SocialCycle will be to have up-todate information in order to be meaningful for its users. The list of bike lanes is widely available for the City of the Sydney but other non-official bike routes are hard to find online. Information and location of facilities useful for riders is hard to find online. To solve this issue, crowdsourcing will be used where user generated content will be made available by the app. Crowdsourcing is used in many other app and describes 
the practice of obtaining needed content by soliciting contributions from a large group of people [20]. Crowdsourcing can be used to gather detailed information about facilities such as showers, bike-racks and secure parking as well as information on safe routes, interesting sights, coffee shops, shortcuts, air pumps and bicycle repair facilities. By sharing this data gathering across an entire group makes it possible to generate a detailed up-to-date dataset, which would be nearly impossible to generate for an independent or governmental organization.

Users will be able to leave tips and rate cycle routes within SocialCycle app, which will improve the recommendation feature in the app. A website will be created to enable users to edit routes manually and more conveniently behind a personal computer. Users will be able to add venues and points of interest within the application.
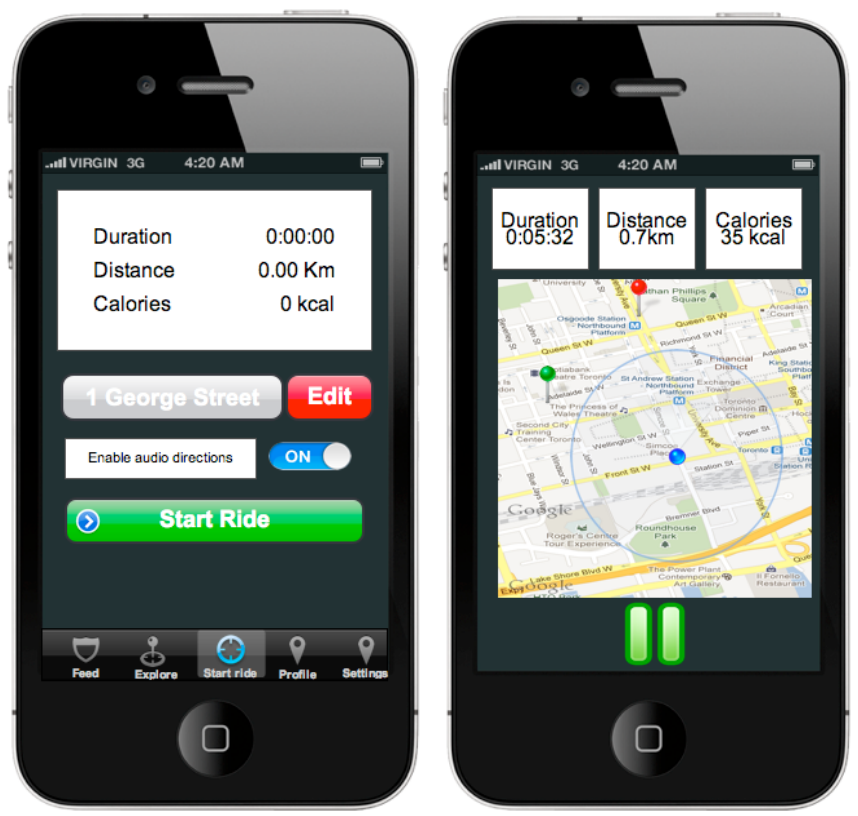

Fig. 2. SocialCycle wireframes

\section{B. Social Information and Social Networking}

A social network is typically defined as a web-based service allowing individuals to construct a profile, establish connections with other users and view those connections. In practice, social networks deliver four main benefits:

1. Information sharing across time and geographic constraints.

2. Formation of emotional support networks.

3. Entertainment and relaxation via gaming and relationships with other like-minded individuals.

4. Mechanisms to assist in the delivery of advice from friends or colleagues. The same benefits also apply in the context of mobile-based social networks.

In the context of cycling, social networking can provide users with multiple benefits such as: the ability to identify with other cyclists and feel a sense of community, a support network to encourage positive behaviors and maintain motivation, an environment to engage in friendly play or compete against other cyclists, a network of informed friends and colleagues to provide local information on facilities and routes, as well as a forum to make goals public and be held accountable to others. These aspects are further detailed below.

Locating Friends and Cycling Companions: One objective of the City of Sydney is to improve the confidence level of cyclists. The survey showed that users want to be able to connect with friends or other cyclists to ride together. Before or during a trip, users will be able to see the location of their friends on the map. This allows riders to hook up with others and ride together which in turn will make them feel more confident.

Improving routes by leaving tips: Cyclists will be able to rate the route they cycled and leave tips. This will enable us to improve the algorithms for better routes to users of the app.

To drive more people into using the SocialCycle app, social media will be deeply integrated. Integration with Facebook allows for easier and faster user registration and by using basic information such as gender and age enables us to recommend riders that share the same interests. The user will have the possibility to share the ride with others via Facebook and Twitter. This enables us to catch the attention of their friends and followers and encourage more people to ride. Additionally, users will be able to share pictures of their trip on Facebook, Twitter and Instagram.

\section{Gamification}

Gamification is used in a wide range of applications to encourage participation and engagement. By using game mechanics, the objective is to have users returning to your application more often. In the context of cycling, gamification can provide users with immediate access to specific rewards that help to reinforce behaviors and build positive associations with cycling. For the SocialCycle app we decided to focus on attracting, retaining and engaging users.

Leaderboards bring an element of competition within the application by comparing your score on a daily, weekly, monthly or yearly basis. Leaderboards are used to track and display desired actions and help users see how they are doing compared to others. An example would be kilometers cycled in a particular week. Different leaderboards are available such as points accumulated (see Fig. 3 below), total distance cycled and calories burned. 


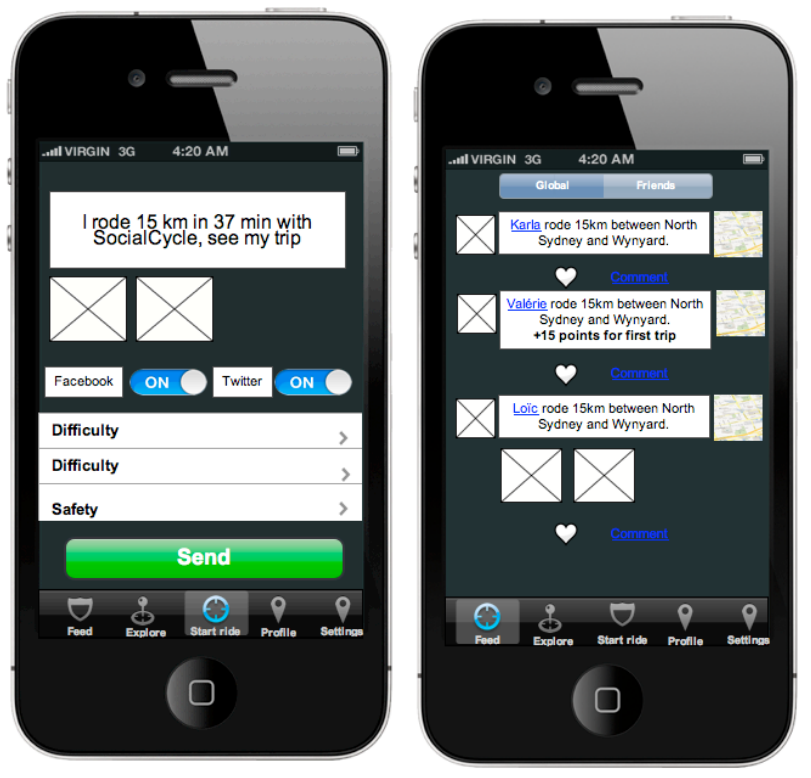

Fig. 3. Wireframes for social aspects

Points: People love to be rewarded and points are an easy way to achieve this. By adding a point system users can be rewarded if they achieve a certain goal. This can be multidimensional by grating points across different actions. For example, extra 5 points for riding $10 \mathrm{~km}$ in one day. We use a monthly point system for SocialCycle since the number of rides will be generally low (typically a few rides a week).

Levels: Different levels (rookie, amateur, expert, champion etc.) are introduced to foster engagement within the app and also improve better content. If a user, for example, posts insightful tips and uploads pictures frequently he can be upgraded to "expert".
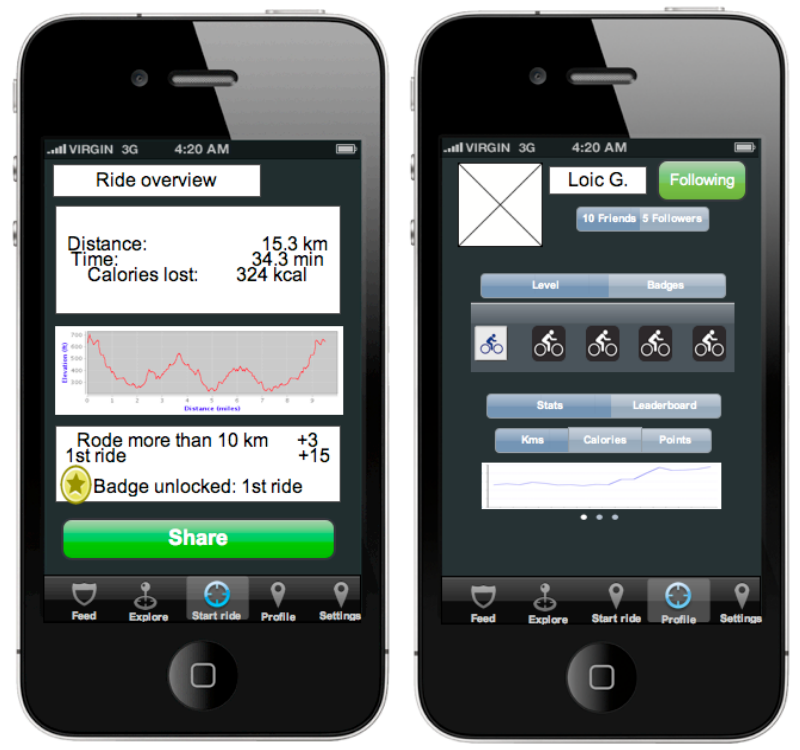

Fig. 4. Wireframes for gamification
Quests and badges: Introducing Quests and badges to the app gives users certain missions to achieve by performing certain tasks. Quests and badges can be unlocked individually or within a group of people. Examples are The Foodie Track Badge or Sydneysiders $1,000 \mathrm{~km}$ ride.

\section{Prototype SocialCycle}

We used the Ride2Work ${ }^{1}$ initiative to build and trial the SocialCycle app. The app focused around the social aspects as discussed before. SocialCycle allows users to discover and connect with other cyclists so that they can ride to work together. Using the app, the users are able to choose when and where they would meet. The app enables and encourages people who have little or no riding experience to ride to work by connecting them with more experienced cyclists. Furthermore, pre-determined safe cycle routes from various meeting points into the University of Technology, Sydney (UTS) were provided. This allows novice cyclists to feel safe and comfortable while learning their way to UTS on their bicycles. Another key objective of SocialCycle is to collect feedback and suggestions from participants to validate our research and improve the app.

The app was developed for Android smartphones and connects to a backend server. The communication between the server and the mobile app is based on the JSON protocol.

The server uses standard database mechanisms to store user data and also stores dynamic data such as the users' current position (submitted from the mobile app) and their current group assignment. A simple matching algorithm is used to correlate the latest user data and sends regular update information to the mobile app.

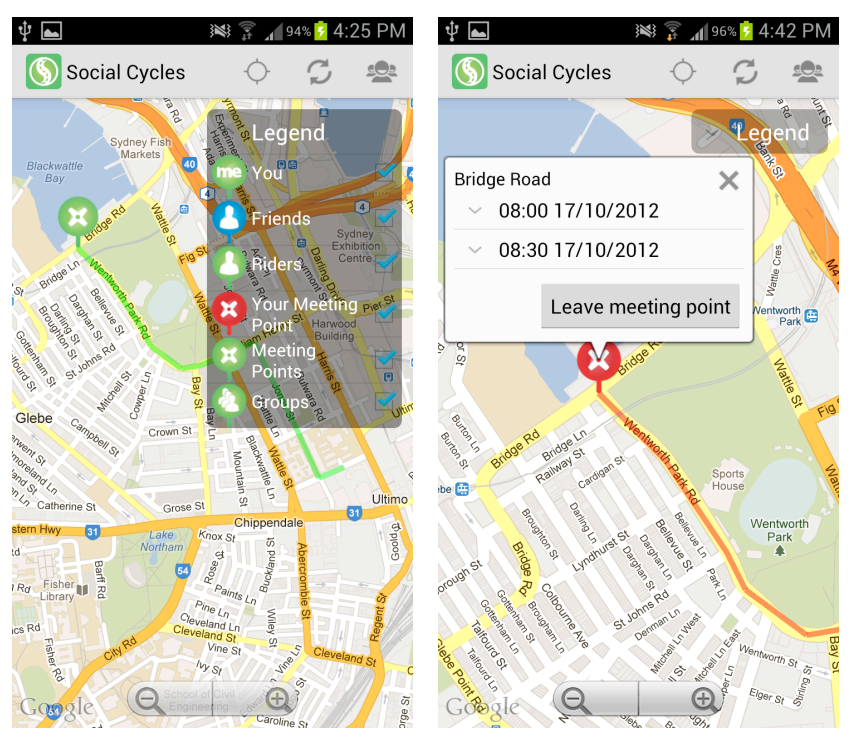

Fig. 5. Meeting points

${ }^{1}$ The Ride2Work Program aims to get people started and keep them riding to work using bicycles. 
The mobile app uses standard Android UI components and uses the Google Maps service for displaying the users' position and the cycle routes to UTS. A user needs to register first and is then presented with a map (Fig. 5 left) showing the positions of other riders/friends and also the various meeting points.

The user can select a meeting point (Fig. 5 right) and sign up to meet at that meeting point at a particular time. Each meeting point has a set of time slots where cyclists can meet and then cycle together to UTS.
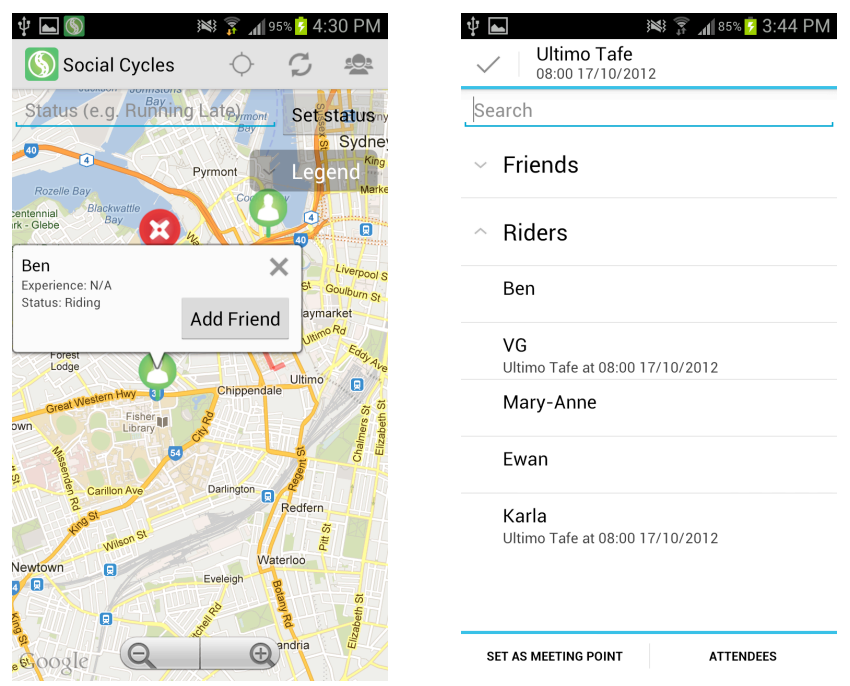

Fig. 6. Real-time location of cyclists \& friends in SocialCycle

The app shows the location of other cyclists in real time so that they can choose a group to ride with if they cannot make it to a meeting point (Fig. 6 left). Users can also set other riders as friends, allowing them to easily see where they currently are.

\begin{tabular}{l} 
Event \\
\hline Ride2UTS Day \\
Date \\
Wednesday 17 October \\
Information \\
Ride your bike and come to the free \\
breakfast between 8-9:30am at the entrance \\
to the Tower Building. \\
Bike Parking \\
Bike parking can be located at: \\
- Multi-Purpose Sports Hall, (CB04B), enter \\
via level 1, Building 3, off Harris Street \\
- Building 10 In carpark, via Thomas Street \\
- Haymarket, Building 5, Block A adj. Darling \\
Drive, requires security application \\
- Haymarket, Building 5, Block B, unsecured \\
racks \\
Showers \\
For after the ride, there are showers too! \\
Location Comments \\
CB01.21C Unisex Shower
\end{tabular}

\begin{tabular}{|c|c|}
\hline \multicolumn{2}{|c|}{$\Psi$ 回 } \\
\hline \multicolumn{2}{|c|}{ Event information } \\
\hline \multicolumn{2}{|c|}{ Showers } \\
\hline \multicolumn{2}{|c|}{ For after the ride, there are showers too! } \\
\hline Location & Comments \\
\hline CB01.21C & Unisex Shower \\
\hline CB01.02.16C & Locker Room /Shower \\
\hline СB01.02.16D & Female Toilet /Shower \\
\hline CB01.06.06A & $\begin{array}{l}\text { Male Shower and Change } \\
\text { Room }\end{array}$ \\
\hline CB02.01.11 & $\begin{array}{l}\text { Male Change Room / Shower } \\
\text { (students) }\end{array}$ \\
\hline CB02.01.12A & $\begin{array}{l}\text { Male Change Room / Shower } \\
\text { (staff) }\end{array}$ \\
\hline СВ02.02.08 & Female Toilet /Shower \\
\hline $\mathrm{CB} 02.10 \mathrm{~A}$ & Male Toilet / Shower \\
\hline CB02.03.15C & $\begin{array}{l}\text { Disabled, Unisex Toilet / } \\
\text { Shower }\end{array}$ \\
\hline \multicolumn{2}{|c|}{ CB02.03.90A/BMale Change/Showers } \\
\hline CB03.01.08 & Unisex Shower (pin access) \\
\hline CB04.01.02 & $\begin{array}{l}\text { Male Toilet / Shower (UTS } \\
\text { Fitness Center - Paid entry) }\end{array}$ \\
\hline
\end{tabular}

Fig. 7. Event information \& facilities

The app shows detailed information about the event and outlines the facilities available at the destination (Fig. 7). The information is specific for cyclists and is automatically updated for each cycling event.

\section{DISCUSSION}

The results obtained from the survey show a wide number of barriers and incentives that governments and communities should consider for a wide adoption of cycling in the City of Sydney.

All the survey participants regard mobile applications as a potential tool to enable, engage and encourage cycling in the city of Sydney. It could effectively act as a catalyst towards this behavioral change based on the 4Es theory depicted in Fig. 8.

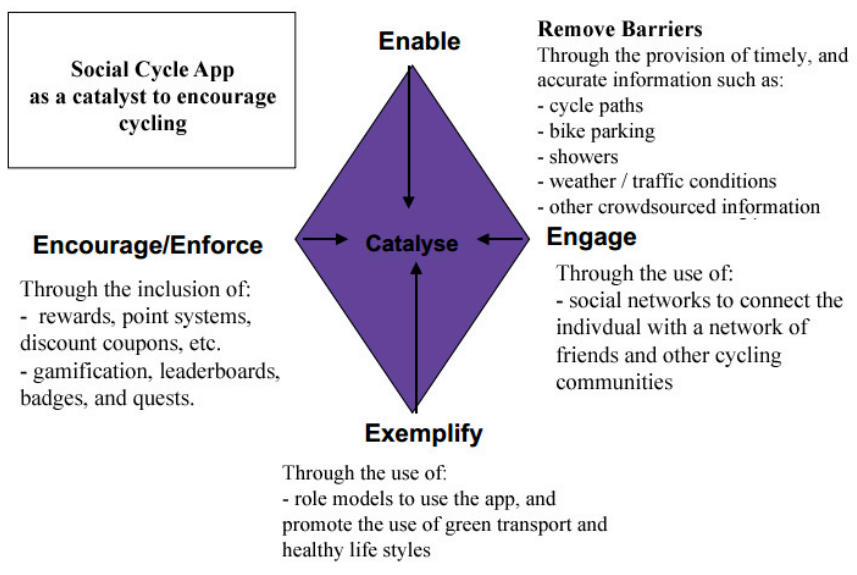

Fig. 8. Personalization in SocialCycle

Enable: Some barriers involving city infrastructure, such as cycle paths, secure parking, public showers, etc. Among others, need to be addressed by the city. They require a long-term investment in resources from government, city councils and communities alike; however, many other barriers such as the lack of information about cycling routes, cycling facilities or services can be addressed by using mobile apps. SocialCycle includes the provision of route information and the location of some of the relevant services such as bike parking and showers.

Engage: No surprisingly, the social factor, namely the use of social networks scored high as an engaging tool among our participants. It is one of the most popular communication tools among the youth and adult population worldwide. SocialCycle is designed and developed with this engaging element in mind. Cyclists can find other friends to ride with, either for companionship, safety, to be part of a community, and/or to learn from each other's expertise and experience.

Encourage and Enforce: Since gaming technology, competition and/or rewards can encourage and enforce cycling. $60 \%$ of the survey participants showed interest in some sort of reward when they cycle, they will be included in the next version of SocialCycle.

Exemplify: This aspect was not incorporated in the current version of SocialCycle but will be in the future in the form of role models and leaders utilizing mobile applications as a tool 
to advertise, lead or encourage participation in events promoting transport sustainability.

Legal and safety aspects. Legal aspects cannot be underestimated, and they need to be addressed during the app development. Safety is another very important element to take into account while designing a cycling mobile app. For safety reasons, SocialCycle uses voice directions, and included voice recognition. It also provides important recommendations on the safe use of mobile technologies while riding in the city.

\section{REFERENCES}

Note: All the websites have been viewed on the 29th of July 2013

[1] C.R. May et al. "Development of a theory of implementation and integration: Normalization Process Theory. Implementation Science". 2009; 4 art 29. http://www.biomedcentral.com/content/pdf/1748-5908-4-29.pdf

[2] Australia Bureau of Statistics, "Causes of Death, Australia, 2009 “, 2009.

http://www.abs.gov.au/ausstats/abs@.nsf/Products/2BC6B190A FE618D2CA25788400127BBC?opendocument

[3] NSW department of planning, "NSW state and regional population projections, 2006, 2036, 2008 release". http://www.planning.nsw.gov.au/population/pdfs/nsw state regi onal population projections 20062036 2008release.pdf

[4] Department of environment and climate change NSW, "NSW cleaner vehicle and fuel strategy", http:/www.environment.nsw.gov.au/resources/air/actionforair/cl eanervehicles08327.pdf

[5] Australian Government, Department of transport and regional services, "Estimating Urban Traffic and Congestion cost trends for Australian cities, http://www.bitre.gov.au/publications/2007/files/wp 071.pdf

[6] T. Edwards and S. Smith, "Transport Problems facing large cities" Briefing paper no 6/08, NSW parliamentary Library research service, http://www.parliament.nsw.gov.au/prod/parlment/publications.n sf/key/TransportProblemsFacingLargeCities/\$File/TransportFIN ALindex.pdf

[7] NSW government, Sydney cycle strategy and action plan, http://www.bicycleinfo.nsw.gov.au/downloads/council bikeplan s/sydney ccl cycle strategy and action plan 2007-2017.pdf

[8] City of Sydney, transport information, http://www.cityofsydney.nsw.gov.au/AboutSydney/ParkingAnd Transport/Cycling/

[9] UK Sustainable Development Strategy, "Securing the Future $^{\text {ee }}$ Defra, 2005, https://www.gov.uk/government/uploads/system/uploads/a ttachment data/file/69412/pb10589-securing-the-future050307.pdf

[10] Endomondo, http://www.endomondo.com/

[11] Runkeeper, www.runkeeper.com

[12] Mapmyride, http://www.mapmyride.com/

[13] iBike, https://itunes.apple.com/au/app/ibike/id369550718?mt=8

[14] Cyclemeter, http://itunes.apple.com/us/app/cyclemeter-gps-bikecomputer $/ \mathrm{id} 330595774 ? \mathrm{mt}=8$

[15] Spokes NYC, http://i.nycbikemaps.com

[16] Strava, www.strava.com

[17] D. Sygall, "Strava highlights dangers of "social fitness"”, Sydney Morning Herald, 2013. http://www.smh.com.au/executive-style/fitness/strava-highlightsdangers-of-social-fitness-20130304-2ffkj.html

[18] Waze, www.waze.com

[19] Survey results, https://docs.google.com/spreadsheet/pub?key=0AhtdJ1A0LrM WdElGdDUzNXJ4TUdlcWhJY2diQWpUemc\&output=html

[20] Crowdsourcing definition, www.merriam-webster.com/dictionary/crowdsourcing 